\title{
Nursing and organizational barriers to daily interruption of sedation in U.S. hospitals: A thematic review of the literature
}

\author{
Pam Baker DeGuzman ${ }^{* 1}$, Carol A. Wayner ${ }^{2}$ \\ ${ }^{1}$ School of Nursing, University of Virginia, Charlottesville, VA, United States \\ ${ }^{2}$ Martha Jefferson Hospital, Charlottesville, VA, United States
}

Received: October 14, 2014

DOI: $10.5430 /$ cns.v3n1p55
Accepted: November 11, 2014 Online Published: November 24, 2014 URL: http://dx.doi.org/10.5430/cns.v3n1p55

\begin{abstract}
Despite focused attention on hospital-acquired infections, ventilator-associated pneumonia (VAP) infections and deaths continue to be a problem in U.S. hospitals. Research indicates that protocols are in place across hospitals but actual implementation lags behind. The inconsistencies in protocol implementation may be due to workarounds created during the process of daily interruption of sedation (DIS), which is the process of stopping the ventilated patient's sedation at a prescribed time each day to evaluate the patient's ability to wean. The purpose of this thematic synthesis of the literature was to understand how nursing and organizational barriers may affect adherence to DIS protocols in U.S. hospitals. We conducted a search using the Cumulative Index of Nursing and Allied Health Literature, using terms related to sedation and mechanical ventilation, then coded and categorized the study findings, and developed themes. Three themes emerged: (1) organizational structure does not influence DIS at either the hospital or unit level, (2) a collaborative, multidisciplinary culture may be needed to influence changes in sedation practices, and (3) the gap between evidence and practice may be due to lack of nursing education and experience. To improve outcomes, intensive care units should evaluate the impact of multidisciplinary ventilator rounding teams that include nursing, on DIS adherence and VAP rates, and ensure that nurses are up-to-date on the evidence around all aspects of sedation management.
\end{abstract}

Key Words: Ventilator-associated pneumonia, Ventilator weaning, Critical care nursing, Systematic review

\section{Introduction}

Despite focused attention on hospital acquired infections, ventilator-associated pneumonia (VAP) infections and deaths continue to plague U.S. hospitals. In 2012, VAPs were associated with nearly 4,000 infections in National Healthcare Safety Network facilities. ${ }^{[1]}$ Ventilator weaning protocols have been shown to improve patient outcomes, ${ }^{[2-4]}$ although the evidence is inconsistent. ${ }^{[5]}$
Research indicates that protocols are in place across hospitals $;{ }^{[4,6-8]}$ however, while practitioners verbalize that they follow the protocols, research has indicated that actual implementation lags behind..$^{[4,6-8]}$ The inconsistencies in protocol implementation and outcomes may be due to workarounds created due to protocol complexity, ${ }^{[6]}$ and may be occur during daily interruption of sedation (DIS). DIS is the process of stopping the ventilated patient's sedation at a prescribed time each day to evaluate the patient's ability to

\footnotetext{
*Correspondence: Pam Baker DeGuzman; Email: deguzman@virginia.edu; Address: University of Virginia School of Nursing, PO Box 800782, Charlottesville, VA 22908, United States.
} 
wean, and is an integral part of weaning protocols. The process allows a reduction in sedative analgesics, while maintaining patient comfort, and an assessment of patient tolerance of the sedation reduction. ${ }^{[2]}$ Nurses assess patients' ability to tolerate weaning, and either completely stop the sedation or restart it at a reduced rate.

Nurses are critical to successful sedation weaning. In a study comparing two groups of ventilator-assisted patients who were weaned following different protocols, 197 medical ICU patients were weaned using a multi-disciplinary protocol that nurses implemented, and 226 patients were weaned with the standard physician-driven protocol. Patients weaned with the nurse-driven multidisciplinary protocol had lower VAP rates and fewer ventilator days. ${ }^{[9]}$ A subsequent study found a higher rate of successful extubation among patients weaned with a nurse-driven protocol. ${ }^{[10]}$

Hospitals with structures and cultures that are supportive of patient care and nursing have been shown to be associated with better patient outcomes, including respiratory outcomes. A broadly recognized example is the Magnet Recognition Program ${ }^{\circledR}$, which designates hospitals that have positive traits, including a collaborative culture. ${ }^{[11]}$ These organizational behavior qualities are linked to better patient outcomes including lower mortality, ${ }^{[12]}$ and lower rates of pneumonia. ${ }^{[13]}$

Two literature reviews have examined aspects of DIS implementation. One review of DIS evaluated barriers to implementation; however, the authors did not approach the review systematically, and did not differentiate between the experiences of various types of clinicians. ${ }^{[14]}$ Because the nursing role in DIS protocols is separate and distinct from that of physicians, pharmacists, and respiratory therapists, it is critical to evaluate these impacts separately. The review also did not evaluate organizational-level characteristics as barriers to DIS. Another review explored adherence to sedation withdrawal protocols and guidelines, but was limited to caregiver perceptions and complexity of care, and did not investigate the impact of interdisciplinary collaboration and organizational culture. ${ }^{[6]}$

\section{Purpose}

When processes for DIS are either not followed in a standardized way or not followed at all, patients are at increased risk of extensive ventilator days and VAP. With the intense focus on reducing VAP rates across hospitals, it is important to have a comprehensive analysis of the existing literature focused on the impact of nursing and organizational characteristics on DIS implementation. The purpose of this review was to understand how nursing and organizational barriers may affect adherence to DIS protocols. Findings from this review may be used to develop hypothesis around improving DIS protocol adherence.

\section{Methods}

A thematic synthesis of the literature was conducted. According to Lucas and colleagues, thematic synthesis is one method of literature review that allows a synthesis of qualitative and quantitative data. Because our review would potentially include both qualitative and quantitative articles, we chose this method, which groups data into themes, and can be used when new hypotheses need to be developed. ${ }^{[15]}$ We searched the Cumulative Index of Nursing and Allied Health Literature (CINAHL) for literature that addressed nursing or organizational barriers to implementation of sedation protocols. Although our focus was DIS, there is limited research on this topic; thus, we included factors affecting implementation of any aspect of sedation protocols, to glean potential insights into DIS. Our search strategy used the following keywords ([MH "Ventilation, Mechanical, Differentiated"] or [MH "Mechanical Ventilation (Iowa NIC)"] or [MH "Ventilator Weaning"] or ["Mechanical Ventilation"] or [MH "Ventilator Patients"] and [MH "Sedation"]), then limited to research articles and English language, revealing 109 articles. After limiting our search to those articles that were published in the last 10 years to capture research conducted on the sedation interruption component of protocols, 91 articles remained.

Two authors (P.B.D. and C.A.W.) collaboratively evaluated the titles and abstracts of the articles, identifying those that addressed nursing or organizational barriers to sedation weaning protocols. Review articles were not included, but evaluated along with selected articles for an ancestral search. The authors discussed differences of opinion and came to consensus on the selection of articles for this review. After limiting our search to these criteria, we identified seven articles from the CINHAL review, and an additional two from the ancestral search.

Data from the reviewed articles, including type of study, sample and setting, data collection methods, outcome variables, were abstracted. Findings were coded, and categories of factors influencing success of DIS protocols were collaboratively developed. Coding and categorization disagreements were resolved through discussion, and categories of factors influencing success of DIS protocols were developed into themes.

\section{Results}

Nine articles were analyzed and are presented in Table 1. The earliest article was from 2006 and the most recent was from 2013. All of the articles were authored by multidisciplinary groups; only one did not include at least one nurse as an author, ${ }^{[7]}$ and one did not include a physician. ${ }^{[15]}$ Other disciplines included among authors were pharmacy and social work. ${ }^{[7,8,17,18]}$ The studies were conducted in a variety of geographical locations including the U.S., ${ }^{[17-21]}$ and Denmark; ${ }^{[22]}$ others covered multiple countries or regions. ${ }^{[7,8,16]}$ 
The majority of these studies evaluated the beliefs of physicians and nurses. ${ }^{[7,16,17,22]}$ Two surveyed only nurses. ${ }^{[18,19]}$

The majority of the studies were descriptive. Five of the studies measured practitioners' perceptions of barriers and attitudes toward DIS, ${ }^{[7,16-19,22]}$ and one measured practitioners' attitudes about delirium management and outcomes. ${ }^{[8]}$ Two of the nine studies used inferential methods. One evaluated the relationship of organizational culture on use of DIS, ${ }^{[21]}$ and one that utilized chart review to determine the effect of a multidisciplinary ventilator bundle team on compliance with sedation-related protocols. ${ }^{[20]}$

\subsection{Categorical analysis}

Seven categories of factors influencing success of DIS protocols were identified: (1) lack of communication, (2) difference in beliefs, (3) lack of collaboration, (4) differences in practice, (5) multidisciplinary teams, (6) organizational characteristics, and (7) organizational structure.

\subsection{Thematic analysis}

The information derived from the categorical analysis was developed into themes. The themes were (1) organizational structure does not influence DIS at either the hospital or unit level (2) a collaborative, multidisciplinary culture may be needed to influence changes in sedation practices, and (3) the gap between evidence and practice may be due to lack of nursing education and experience.

\subsubsection{Organizational structure does not influence DIS at either the hospital or the unit level}

Little evidence exists that examines the influence of organizational structure on DIS outcomes, and of the two studies reviewed, both examined the effect of structure at the hospital and unit level. Miller and colleagues surveyed 386 lead infectious disease practitioners from randomly selected U.S. hospitals. ${ }^{[17]}$ They found that elements of hospital structure (size, academic affiliation and number of ICU beds) did not influence DIS use. Their conclusion was reinforced by a survey of 348 Australian and New Zealand ICU physicians and nurses in which no difference in DIS use was found between different size ICUs, or among Australian counties, states, or territories. ${ }^{[16]}$

\subsubsection{A collaborative, multidisciplinary culture may be needed to influence changes in sedation practices}

Research has demonstrated that in many cases, physicians and nurses perceived their sedation decisions as being made collaboratively, and this multidisciplinary collaboration may a positive effect on sedation outcomes. Guttormson's study of sedation perceptions among ICU nurses revealed that $84 \%$ believed that physicians considered the nursing assessment when writing sedation orders, and $60 \%$ felt that nurses and physicians had clear communication around sedation goals. ${ }^{[19]}$ Egerod's study had similar findings, with nurses reporting their perception that most decisions were made collaboratively between physicians and nurses. ${ }^{[22] ~ M e n d e z ~ a n d ~ c o l l e a g u e s ~ e x a m i n e d ~ v e n t i l a t o r ~}$ outcomes between a multidisciplinary ventilator rounding team, including physicians, nurses, respiratory therapists, and pharmacists providing real-time feedback to nurses; compared to the standard intensive care unit rounding team in a MICU. ${ }^{[20]}$ Compliance with the DIS protocol was higher for the multidisciplinary rounding team $(62 \%)$ than for the usual ICU rounding team (54\%).

Despite the documented positive effects of multidisciplinary collaboration, there continues to be a lack of collaboration around patient sedation practices, particularly between physicians and nurses. In a survey of 904 members of the Society of Critical Care Medicine (including physicians, nurses and pharmacists), Tanios and colleagues analyzed the most commonly cited barriers to use of DIS. One of the top barriers cited was lack of nursing acceptance of the protocol, with almost $60 \%$ of respondents citing this as one of the top 3 barriers. ${ }^{[7]}$ The findings did not differentiate responses according to profession, but $69 \%$ of the respondents identified as physicians; thus, it is possible that the physicians were concerned about nursing's acceptance of the DIS protocols. Guttormson and colleagues found that despite nurses reporting clear communication about sedation goals between nurses and physicians, $46 \%$ of nurses did not in fact agree with physicians regarding the ordered level of sedation. ${ }^{[19]}$ Similarly, Egerod found that ICU physicians and nurses reported that most decisions were made collaboratively; nevertheless, twice as many physicians than nurses perceived decisions as being made during conferences that only physicians attended. ${ }^{[22]}$ O'Connor and colleagues found that $50 \%$ of respondents reported restarting sedation during DIS at the nurse's discretion. However, the response did not differentiate between physicians and nurses, and with $75 \%$ of the respondents being nurses, it is difficult to discern if physicians, nurses, or both have this perspective. ${ }^{[16]}$

There is limited literature addressing the influence of unit and hospital culture on sedation practices. In one study, both a leadership-driven safety culture and staff receptivity to change were associated with regular self-reported DIS use. ${ }^{[17]}$ In the qualitative portion of another study, respondents described unit culture as having a strong influence on nurses' and physicians' sedative and analgesic rates and doses. ${ }^{[16]}$

\subsubsection{Gap between evidence base and practice may be due to lack of nursing education and experience}

Using focus groups of physicians, nurses and respiratory therapists, Miller and colleagues found only one shared belief: that every patient should be considered eligible for sedation interruption every day. ${ }^{[17]}$ Practitioners from different disciplines lacked a shared understanding of why to 
perform DIS when weaning. Reasons for performing DIS included weaning from the ventilator, minimizing sedation medications, performance of neurologic examination, evaluation of pain, and reducing length of stay. Even though physicians and nurses were relatively congruent in these reasons for performing DIS, physicians thought that other professionals had different goals for DIS, and there was no consensus between physicians and nurses about the prioritization of these goals. In addition, although they agreed with the other reasons for conducing DIS, respiratory therapists' goals were predominantly governed by achieving ventilator weaning. Egerod and colleagues ${ }^{[22]}$ also identified disagreement between physicians and nurses regarding their beliefs about the side effects of sedatives and analgesics. They found that nurses perceived more gastrointestinal side effects related to sedatives, and physicians perceived more respiratory depression with regard to analgesics. Guttormson and colleagues ${ }^{[19]}$ found that nurses have consistent knowledge about many signs of over and undersedation, but they differed widely in other areas of knowledge. In particular, they differed in their interpretation of a patient's sedation level related to their ability to follow commands. When a patient could not follow commands, more than half of the nurses concluded that the patient was oversedated; while over one-third of nurses disagreed with this conclusion. Nearly half thought that a patient's elevated blood pressure and heart rate meant that the patient was undersedated, but more than one-quarter did not come to this conclusion. Similarly, more than half concluded that if a patient was spontaneously moving their trunk and legs, they were undersedated if they were, but nearly one-third disagreed. Lastly, $61 \%$ agreed that limiting patient recall of the ICU was a goal of sedation, even though Ethier ${ }^{[23]}$ found no differences in patient recall between patients who received a DIS protocol and those who did not.

Table 1: Characteristics of reviewed literature

\begin{tabular}{|c|c|c|c|c|}
\hline Setting & Source & Design & $\begin{array}{l}\text { Data collection } \\
\text { method }\end{array}$ & $\begin{array}{l}\text { Factors influencing } \\
\text { success of DIS } \\
\text { implementation }\end{array}$ \\
\hline ICUs & $\begin{array}{l}\text { Egerod, Christensen, \& Johansen, } 2006 \\
\text { (Denmark) }\end{array}$ & $\begin{array}{l}\text { Cross-sectional } \\
\text { Descriptive Comparative }\end{array}$ & $\begin{array}{l}\text { Self-administered } \\
\text { questionnaire }\end{array}$ & $\begin{array}{l}\text { Lack of Communication } \\
\text { Differences in Beliefs }\end{array}$ \\
\hline ICUs & $\begin{array}{l}\text { Guttormson, Chlan, Weinertb, \& Savik, } 2010 \\
\text { (U.S.) }\end{array}$ & Descriptive Associational & $\begin{array}{l}\text { Self-administration } \\
\text { of Nurse Sedation } \\
\text { Practices Scale }\end{array}$ & $\begin{array}{l}\text { Lack of Collaboration } \\
\text { Differences in Beliefs } \\
\text { Differences in Practice }\end{array}$ \\
\hline Medical ICU & $\begin{array}{l}\text { Mendez, Lazar, DiGiovine, Schuldt, Behrendt, } \\
\text { Peters, \& Jennings, } 2013 \text { (U.S.) }\end{array}$ & $\begin{array}{l}\text { Retrospective } \\
\text { Correlational }\end{array}$ & $\begin{array}{l}\text { Electronic chart } \\
\text { review }\end{array}$ & Multidisciplinary Teams \\
\hline $\begin{array}{l}\text { Hospitals with at least } \\
50 \text { beds and an ICU }\end{array}$ & $\begin{array}{l}\text { Miller, Krein, Saint, Kahn, \& Iwashyna, } 2012 \\
\text { (U.S.) }\end{array}$ & $\begin{array}{l}\text { Descriptive Stratified } \\
\text { Random Sample }\end{array}$ & Survey & $\begin{array}{l}\text { Organizational } \\
\text { Characteristics }\end{array}$ \\
\hline Medical ICU & Miller, Bosk, Iwashyna, \& Krein, 2012 (U.S.) & Qualitative Exploratory & Focus groups & Differences in Practice \\
\hline ICUs & $\begin{array}{l}\text { O’Connor, Bucknall, \& Manias, } 2010 \\
\text { (Australian and New Zealand) }\end{array}$ & $\begin{array}{l}\text { Cross-sectional } \\
\text { Descriptive }\end{array}$ & $\begin{array}{l}\text { Internet-based } \\
\text { survey }\end{array}$ & $\begin{array}{l}\text { Organizational } \\
\text { Characteristics } \\
\text { Differences in Practice }\end{array}$ \\
\hline ICUs & $\begin{array}{l}\text { Patel, Gambrell, Speroff, Scott, Pun, Okahashi, } \\
\text { Strength, Pandharipande, Girard, Burgess, } \\
\text { Dittus, Bernard, Ely, } 2009 \text { (North America) }\end{array}$ & Descriptive & Survey & Differences in Practice \\
\hline $\begin{array}{l}\text { Academic Medical } \\
\text { Center ICUs }\end{array}$ & $\begin{array}{l}\text { Roberts, de Wit, Epstein, Didomenico, \& } \\
\text { Devlin, } 2009 \text { (U.S.) }\end{array}$ & Qualitative Descriptive & Interviews Survey & $\begin{array}{l}\text { Nursing characteristics } \\
\text { Patient characteristics }\end{array}$ \\
\hline ICUs & $\begin{array}{l}\text { Tanios, de Wit, Epstein, \& Devlin, } 2009 \\
\text { (International) }\end{array}$ & Descriptive & Survey & $\begin{array}{l}\text { Lack of Collaboration } \\
\text { Organizational Structure } \\
\text { Multidisciplinary Teams }\end{array}$ \\
\hline
\end{tabular}

DIS = Daily interruption of sedation; ICU = Intensive Care Unit

The articles reviewed also revealed a variety of practices around sedation management. Despite the availability of DIS protocols and knowledge of their benefit, two studies have documented their limited use. Patel conducted a survey of ICU practitioners, and found that over three-quarters had a DIS policy, but less than half practiced DIS more than half the days. ${ }^{[8]}$ O'Connor and colleagues also found that $65 \%$ of respondents felt that DIS was either definitely or most likely to be beneficial to patients. However, just over half of respondents stated that they used it on $25 \%$ or more of their patients, and only $23 \%$ of nurses used it on more than $75 \%$ of their patients. ${ }^{[16]}$ They also found a lack of 
consensus around reasons for determining that patients were unsuitable for DIS. These reasons included unstable neurological status $(43 \%)$, unstable respiratory status $(28 \%)$, or unstable cardiovascular status (18\%). Because $76 \%$ of respondents were nurses, and no breakdown in responses between physicians and nurses was reported, it is difficult to ascertain if nursing, physicians, or the two groups together are creating the barrier to practice change.

Nurses' sedation practices are influenced by their perceptions and beliefs about the patient and family's experience of sedation. In their survey of members of American Association of Critical Care Nurses, Guttormson and colleagues found an overwhelming majority of nurses view mechanical ventilation as both uncomfortable (90\%) and stressful $(92 \%)$ for patients. In addition, nearly half the nurses agreed that a family's request for sedation influenced their sedation practices. They also found that a large majority agreed sedation was necessary for patient comfort $(81 \%)$ and would prefer sedation if they themselves were ventilated $(88 \%) .{ }^{[19]}$ Tanios and colleagues found that one-fifth viewed a patient's potential attempt to remove a device as a barrier to DIS. ${ }^{[7]}$ These findings did not differentiate between physicians, nurses and pharmacists, so it is not possible to determine how this view influences nurse-specific barriers to DIS. Roberts and colleagues surveyed 130 nurses in 2 academic medical centers to determine predictors of DIS use, and found multiple patient-related factors. Nurses were more likely to perform DIS if they perceived the patient to be more stable, if the patient was younger, and if the patient was not admitted with sepsis. They were less likely to perform DIS if the patient was either deeply sedated or had been agitated in the prior 24-48 hour time period. ${ }^{[18]}$

Nursing experience with DIS may be a predictor of DIS implementation, but the research is very limited. Only one study was found that evaluated the characteristics of nursing related to DIS. Roberts and colleagues revealed that nurses were more likely to perform DIS if they had performed DIS either once or more in the past, and there was a trend for nurses to perform DIS if they were younger or had completed CE in the past year related to ICU sedation. ${ }^{[18]}$

\section{Discussion}

The purpose of this review was to understand the nursing and organizational barriers that may affect nursing adherence to DIS protocols. Our review revealed three themes: (1) organizational structure does not influence DIS practice, (2) a collaborative, multidisciplinary culture may influence changes in sedation practices, and (3) the gap between evidence base and practice may be due to differences in nursing education and experience.

Our findings that organizational structure does not influence DIS practice is reflective of some, and in contrast to other, previous research that has examined the impact of organiza- tional structure on VAP rates. One study that reviewed the effect of ICU type (medical versus surgical) on VAP rates in 25 ICUs across eight hospitals found in that ICU type did not have any significant effect on VAP rates. ${ }^{[24]}$ Although our findings were similar, none of the studies in our review evaluated the impact of ICU type on DIS. A study of VAP rates in community hospitals found that rates were higher in small hospitals than in medium or large hospitals. ${ }^{[25]}$ Only one of the studies we evaluated the impact of hospital size on DIS use. Given the literature that suggests that stated DIS use may not be equated with actual use, ${ }^{[4,6-8]}$ hospital size may have no impact on stated use, but an actual impact on adherence to protocols. Additional research is needed to evaluate the impact of hospital size on adherence to DIS protocols, and its subsequent impact on sedation outcomes.

Our synthesis demonstrated that multidisciplinary collaboration may affect sedation practices positively, and lack of this collaboration may have a negative effect on use of DIS protocols. A small body of literature is emerging that demonstrates that unit culture may also have an effect on sedation practices. We found no studies that have examined the impact of a multidisciplinary ICU culture on DIS adherence. Interventional studies are needed that examine how whether an interdisciplinary ventilator rounding team can influence nurses' adherence to DIS protocols, as well as provide additional information about the impact of these teams on infection rates.

Our findings revealed a range of knowledge and beliefs around sedation management and a variety of practices among and within nursing, medicine, and other disciplines. These findings may indicate a lack of evidencebased knowledge and a strong influence of perception of patient's and family's experiences and recent experience and education with sedation management, on sedation management practice. Two studies were found that examined the impact of continuing education on VAP rates and adherence to DIS protocols, with mixed results. A study examining the impact of nurse-led sedation education among 71 ICU nurses found improvements in both nurse compliance with ventilator bundle protocols, and a reduction in VAP rates. ${ }^{[26]}$ Another study using a pre-post design to examine compliance with components of a ventilator bundle among 48 nurses in a 16-bed ICU, found no change in VAP rates. ${ }^{[27]}$ These studies were limited by single ICU settings, with small numbers of patients. Future research should be conducted using larger samples across multiple hospitals to evaluate the impact of education on DIS adherence.

\subsection{Limitations}

This review was limited by several factors. Our methods included only a review of CINAHL literature and any ancestral search stemming from those results. This may have led to the small number of evidence-based studies we found that investigated barriers to DIS. We were also limited in 
our attempt to determine nursing characteristics that may be barriers to DIS because, of the studies we examined, several did not distinguish findings between nursing and other disciplines. Future studies investigating barriers to DIS should recognize not only that DIS is a multidisciplinary effort, but also that the various disciplines play different roles, and therefore may have varying perspectives.

\subsection{Recommendations for practice}

This review suggests the need for nurses to participate in interdisciplinary teams when sedation decisions are being made. Including nurses in daily ventilator rounding teams may be a way to change culture and improve outcomes. Further, our review highlights the need for additional education for nurses around many aspects of sedation administration. Clinicians may lack standardized knowledge about the reasons for and effects of DIS. Nurses want patients to feel comfortable; thus, hospitals need to provide current evidence-based knowledge about aspects of DIS that contribute to or detract from that goal. Combining this education with a multidisciplinary approach may have a larger impact on outcomes.

\section{Conclusion}

Improving patient ventilator-associated outcomes through proper use of DIS requires many disciplines working collaboratively. To improve adherence to protocols, a daily multidisciplinary approach should be considered. The effect of multidisciplinary ventilator rounding teams that include nurses need to be tested to evaluate their impact the adherence to these protocols. Additionally, because many misconceptions may exist around both the patient experience and potential complications of ventilator weaning, nurse educators should ensure that all staff have current education about the evidence about all aspects of sedation management.

\section{References}

[1] Dudeck MA, Weiner LM, Allen-Bridson K, et al. National healthcare safety network (NHSN) report, data summary for 2012, deviceassociated module. Am J Infect Control. 2013 Dec; 41(12): 114866. PMid:24274911. http://dx.doi.org/10.1016/j.ajic. 20 13.09 .002

[2] Kress JP, Pohlman AS, O'Connor MF, et al. Daily interruption of sedative infusions in critically ill patients undergoing mechanical ventilation. N Engl J Med. 2000; 342(20): 1471-7. PMid:10816184. http://dx.doi.org/10.1056/NEJM200005183422002

[3] Brook AD, Ahrens TS, Schaiff R, et al. Effect of a nursingimplemented sedation protocol on the duration of mechanical ventilation. Crit Care Med. 1999; 27(12): 2609-15. http://dx.doi.o $\mathrm{rg} / 10.1097 / 00003246-199912000-00001$

[4] Bucknall TK, Manias E, Presneill JJ. A randomized trial of protocoldirected sedation management for mechanical ventilation in an Australian intensive care unit. Crit Care Med. 2008 May; 36(5): 144450. PMid:18434914. http://dx.doi.org/10.1097/CCM. 0 b013 e318168f82d

[5] Elliott R, McKinley S, Aitken LM, et al. The effect of an algorithmbased sedation guideline on the duration of mechanical ventilation in an Australian intensive care unit. Intensive Care Med. 2006; 32(10): 1506-14. PMid:16896847. http://dx.doi.org/10.10 07/s00134-006-0309-0

[6] Burns SM. Adherence to sedation withdrawal protocols and guidelines in ventilated patients. Clin Nurse Spec. 2012 Jan-Feb; 26(1): 22-8. PMid:22146270. http://dx.doi.org/10.1097/NUR.0b0 $13 \mathrm{e} 31823 \mathrm{bfae} 8$

[7] Tanios MA, de Wit M, Epstein SK, et al. Perceived barriers to the use of sedation protocols and daily sedation interruption: A multidisciplinary survey. J Crit Care. 2009; 24(1): 6673. PMid:19272541. http://dx.doi.org/10.1016/j.jcrc. 20 08.03 .037

[8] Patel RP, Gambrell M, Speroff T, et al. Delirium and sedation in the intensive care unit: Survey of behaviors and attitudes of 1384 healthcare professionals. Crit Care Med. 2009 Mar; 37(3): 82532. PMid:19237884. http://dx.doi.org/10.1097/CCM.0b013 e31819b8608

[9] Quenot J, Ladoire S, Devoucoux F, et al. Effect of a nurseimplemented sedation protocol on the incidence of ventilatorassociated pneumonia. Crit Care Med. 2007; 35(9): 2031-6.

[10] Arias-Rivera S, Sanchez-Sanchez Mdel M, Santos-Diaz R, et al. Effect of a nursing-implemented sedation protocol on weaning outcome. Crit Care Med. 2008 Jul; 36(7): 2054-60. PMid:18552689. http://dx.doi.org/10.1097/CCM.0b013e31817bfd60

[11] American Nurses Credentialing Center. Magnet Recognition Program $®$ Overview [Internet]; 2014 [cited 2014 April 15]. Available from: http://www.nursecredentialing.org/magnet/ programoverview

[12] McHugh MD, Kelly LA, Smith HL, et al. Lower mortality in Magnet hospitals. Med Care. 2013 May; 51(5): 382-8. PMid:23047129. http://dx.doi.org/10.1097/MLR.0b013e3182726cc5

[13] Goode CJ, Blegen MA, Park SH, et al. Comparison of patient outcomes in Magnet $\AA$ and non-Magnet hospitals. J Nurs Adm. 2011 Dec; 41(12): 517-23. PMid:22094616. http://dx.doi .org/10. 1097/NNA . Ob013e3182378b7c

[14] Dotson B. Daily interruption of sedation in patients treated with mechanical ventilation. American Journal of Health-System Pharmacy. 2010; 67(12). http://dx.doi.org/10.2146/ajhp090134

[15] Lucas PJ, Baird J, Arai L, et al. Worked examples of alternative methods for the synthesis of qualitative and quantitative research in systematic reviews. BMC Medical Research Methodology. 2007; 7(4). PMid:17224044.

[16] O'Connor M, Bucknall T, Manias E. Sedation management in Australian and New Zealand intensive care units: Doctors' and nurses' practices and opinions. Am J Crit Care [Internet]. 2010 05; 19(3): 285-95. Available from: http: //search.ebscohost. com/login. aspx?direct=true\&Aut hType $=i p \& d b=c$ in20\&AN=2010649220\&site=ehost - live

[17] Miller MA, Bosk EA, Iwashyna TJ, et al. Implementation challenges in the intensive care unit: The why, who, and how of daily interruption of sedation. J Crit Care. 2012; 27(2): 218.

[18] Roberts RJ, de Wit M, Epstein SK, et al. Predictors for daily interruption of sedation therapy by nurses: A prospective, multicenter study. J Crit Care. 2010; 25(4): 660.

[19] Guttormson JL, Chlan L, Weinert C, et al. Factors influencing nurse sedation practices with mechanically ventilated patients: A U.S. national survey. Intensive Crit Care Nurs. 2010 02; 26(1): 44-50. 
[20] Mendez MP, Lazar MH, Digiovine B, et al. Dedicated multidisciplinary ventilator bundle team and compliance with sedation vacation. Am J Crit Care. 2013 Jan; 22(1): 54-60. PMid:23283089. http://dx.doi.org/10.4037/ajcc2013873

[21] Miller MA, Krein SL, Saint S, et al. Organisational characteristics associated with the use of daily interruption of sedation in US hospitals: A national study. BMJ Qual Saf. 2012 Feb; 21(2): 14551. PMid:21949434. http://dx.doi.org/10.1136/bmjqs-201 1-000233

[22] Egerod I, Christensen BV, Johansen L. Nurses' and physicians' sedation practices in Danish ICUs in 2003: A national survey. Intensive Crit Care Nurs. 2006 02; 22(1): 22-31.

[23] Ethier C, Burry L, Martinez-Motta C, et al. Recall of intensive care unit stay in patients managed with a sedation protocol or a sedation protocol with daily sedative interruption: A pilot study. J Crit Care. 2011; 26(2): 127-32. PMid:20889289. http://dx.doi.org/10. $1016 / j \cdot j$ crc. 2010.08 .003
[24] Manojlovich M, Antonakos CL, Ronis DL. The relationship between hospital size and ICU type on select adverse patient outcomes. Hosp Top. 2010; 88(2): 33-42. PMid:20494883. http: //dx.doi.org/10.1080/00185861003768845

[25] Lee MS, Walker V, Chen LF, et al. The epidemiology of ventilatorassociated pneumonia in a network of community hospitals: A prospective multicenter study. Infect Control Hosp Epidemiol. 2013 Jul; 34(7): 657-62. PMid:23739068. http://dx.doi.org/10.10 $86 / 670991$

[26] Subramanian P, Choy KL, Gobal SV, et al. Impact of education on ventilator-associated pneumonia in the intensive care unit. Singapore Med J. 2013 May; 54(5): 281-4. PMid:23716155. http: //dx.doi.org/10.11622/smedj.2013109

[27] Gatell J, Rosa M, Santé Roig M, et al. Assessment of a training programme for the prevention of ventilator associated pneumonia. Nurs Crit Care. 2012; 17(6): 285-92. PMid:23061618. http: //dx.doi.org/10.1111/j.1478-5153.2012.00526.x 